\title{
TEMPERATURE MEASUREMENT DURING FRICTIONAL SLIDING OF ROCKS
}

\author{
Naoto YosHIOKA \\ Information Processing Center, Yokohama City University, Yokohama, Japan \\ (Received August 10, 1984; Revised June 4, 1985)
}

\begin{abstract}
Experiments on frictional sliding of rock samples, sandstone and granite, were performed in an attempt to investigate the fracturing process and thd energy conservation during sliding. In the experiments, we observed rises in temperature due to frictional sliding, in addition to other basic physical parameters such as displacement, and normal and shear stresses.

Four sliding modes are distinguished: stable sliding, continuous stick-slip with small stress drop, episodic sliding, and violent stick-slip. The sliding mode is strongly affected by the presence of gouges, which tends to make sliding stable and stress drop small.

The temperature rise is remarkably related to the sliding mode which is characterized by the magnitude of stress drop. The temperature data shows that there is non-uniform distribution of heat sources and that the average heat source magnitude varies with the fractional stress drop, which is the ratio of stress drop $\Delta \tau$ to initial stress $\tau_{1}$ before sliding. An empirical relation between the average heat source magnitude $a$ and the fractional stress drop $\Delta \tau / \tau_{1}$ is given by $a=1-\Delta \tau / \tau_{1}$.

The temperature measurement during frictional sliding of rocks in laboratory experiment provides an effective method for investigating the fracturing process and the energy balance in earthquake source mechanism.
\end{abstract}

\section{Introduction}

It is important to understand in detail the process of rock friction before studying the source mechanism of earthquakes, because most shallow focus earthquakes are considered to be shear dislocations of pre-existing faults. A number of field studies have shown that these natural faults are results of ancient seismic faulting (SCOTT and Drever, 1954; ERMANOVICs et al., 1972; ENGELDER, 1974; SiBson, 1975, 1977a; Wu et al., 1975; Scholz et al., 1979; Scholz, 1980; JoHNSTON and WHITE, 1983).

Since BRACE and BYERLEE (1966) proposed the stick-slip instability as a possible mechanism of shallow earthquakes, numerous theoretical and experimental works have been done concerning rock friction. There are many interesting problems concerning stick-slip phenomenon, such as stick-slip to stable sliding transition (e.g., BYerLeE and BraCE, 1968; Scholz et al., 1972; ENGELder et al., 1975), time-dependent effects or effects of strain rate (e.g., BYERLEE and BRACE, 1968; 
SCHOlz et al., 1972; DieTERICH, 1972), effects of gouge composition (SUMmers and BYERLEE, 1977; SHIMAMOTO and LOGAN, 1981), wear process, surface roughness and gouge formation (ENGELDER, 1974; Friedman et al., 1974; OHNAKA, 1975; Barton, 1976; Scholz and ENGelder, 1976; ENGELder and Scholz, 1976), slip velocity (BRUNE, 1970, 1973; HUSSEINI, 1977; OHNAKA, 1978), rupture velocity (Scholz et al., 1972; OHNAKA, 1973; DieTERICH, 1979a; OHNAKA et al., 1983), kinetic resistance during sliding (BARTON, 1976; SIBSON, 1977b, 1980), and effects of machine stiffness (BYERLEE and BrACE, 1968; WALSH, 1971; OHNAKA, 1973; Goodman and Sundaram, 1978). A number of theories and models have been proposed to explain the physical mechanics of stick-slip, based on experimental results (e.g., BYERLEE, 1970; DIETERICH, 1974, 1979a, b; IDA, 1975; SIBSON, 1977a).

In addition, some of the most interesting problems in rock friction are shown in the rise of temperature, which is caused by frictional heating, and in the energy balance on the fault surfaces during sliding. SiBSON $(1977 \mathrm{~b}, 1980)$ discussed the energy balance that occurs during faulting, based on geological evidence. MCKENZIE and BRUNe (1972), Richards (1976), CARDWEll et al. (1978) and LACHENBRUCH (1980) theoretically calculated the temperature rise on the fault plane and discussed the effect of frictional heating on sliding motion. RALEIGH (1977) pointed out the possibility of dehydration mechanism due to frictional heating. TEUFEL and LOGAN (1978) directly observed temperature changes in their experiments through the use of thermo-dyes coated on sliding surfaces of rock samples. Recently YosHIOKA and SHIDAHARA (1978) and LOCKNER and OKUBo (1983) measured the temperature variation in time due to rock friction, making use of thermistors buried in rock samples. LOCKNER and OKUBO (1983) concluded that frictional heat occupies $94 \pm 2 \%$ of the total work done, and that this implies the seismic efficiency of $4-8 \%$.

As briefly summarized above, heat generation, due to frictional sliding, is important for the earthquake source mechanism because heat energy is likely to occupy a significant part of energy supplied by a testing machine in laboratory experiments, and by the Earth in natural faultings.

In a previous paper (YosHIOKA, 1984), a method for estimating the shear stress distribution on sliding surfaces was described. In the present paper, I shall first introduce the experimental method, used to measure temperature rises that are due to frictional sliding, then show the experimental results using the method presented in the previous paper, and finally discuss the relation between stress drop and heat energy.

\section{Experimental Methods}

\subsection{Samples}

Samples selected for our experiments were fine grained sandstones from Choshi, Chiba Prefecture, and granites of intermediate grain from Makabe, Iba- 
Table 1. Mechanical and thermal properties of rock samples.

\begin{tabular}{|c|c|c|c|c|c|c|c|c|}
\hline & \multicolumn{2}{|c|}{ Density } & \multirow{2}{*}{$\begin{array}{c}\text { Porosity } \\
(\%)\end{array}$} & \multicolumn{2}{|c|}{$\mathrm{P}$-wave velocity $(\mathrm{km} / \mathrm{s})$} & \multicolumn{2}{|c|}{ Strength $(\mathrm{MPa})$} & \multirow{2}{*}{$\begin{array}{c}\text { Thermal } \\
\text { diffusivity } \\
\left(\mathrm{cm}^{2} / \mathrm{s}\right)\end{array}$} \\
\hline & dry & wet & & dry & wet & comp.* & ten.** & \\
\hline CHS-SS & 2.31 & 2.43 & $12.3 \pm 0.7$ & $2.61 \pm 0.10$ & $3.28 \pm$ & 65 & 3.6 & $14 \times 10^{-3}$ \\
\hline MKB-GR & 2.65 & 2.67 & $0.75 \pm 0.09$ & $3.85 \pm 0.15$ & $5.27 \pm 0.03$ & 150 & 6.1 & $12 \times 10^{-3}$ \\
\hline
\end{tabular}

* Uni-axial compressive strength. ** Tensile strength measured by Brazilian test.

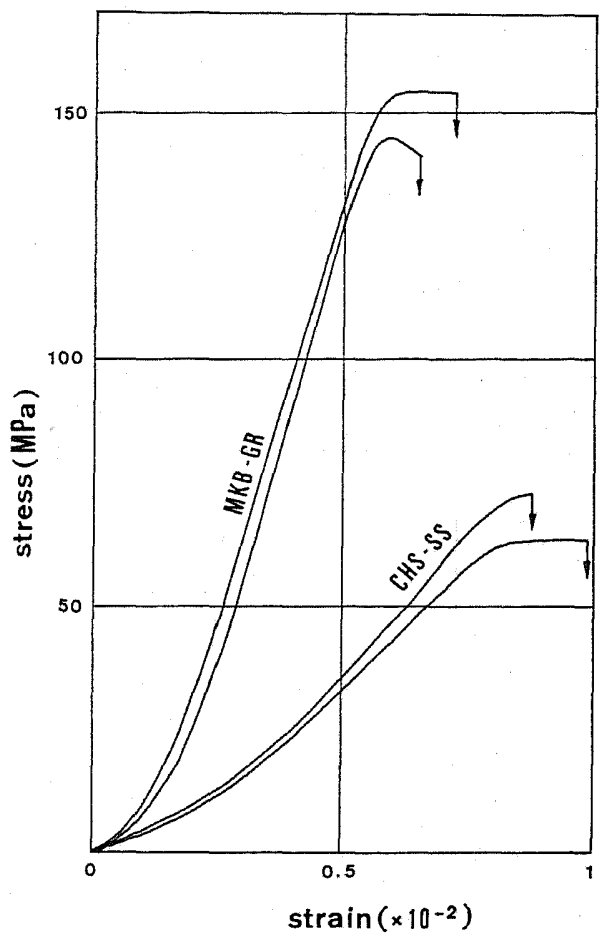

Fig. 1. Stress-strain curves obtained from uni-axial compression tests on core samples of CHS-SS and MKB-GR. The brittle fractures occurred at the points shown by arrows.

raki Prefecture. We hereafter denote the former and the latter samples as CHSSS and MKB-GR, respectively. Table 1 shows some of the mechanical and thermal properties of the samples. The tests for the mechanical properties were conducted on core samples of $5.0 \mathrm{~cm}$ in diameter and $10 \mathrm{~cm}$ in length. The stressstrain curves in uni-axial compression tests are presented in Fig. 1.

The experiments of frictional sliding were performed on a pair of $10 \times 10 \times$ $20 \mathrm{~cm}^{3}$ samples. The parallelism of the sliding surface relative to the opposite side was less than $0.01 \mathrm{~cm} / 20 \mathrm{~cm}$. In order to keep the apparent contact area constant during sliding, the circumferential corner of the upper specimen was 

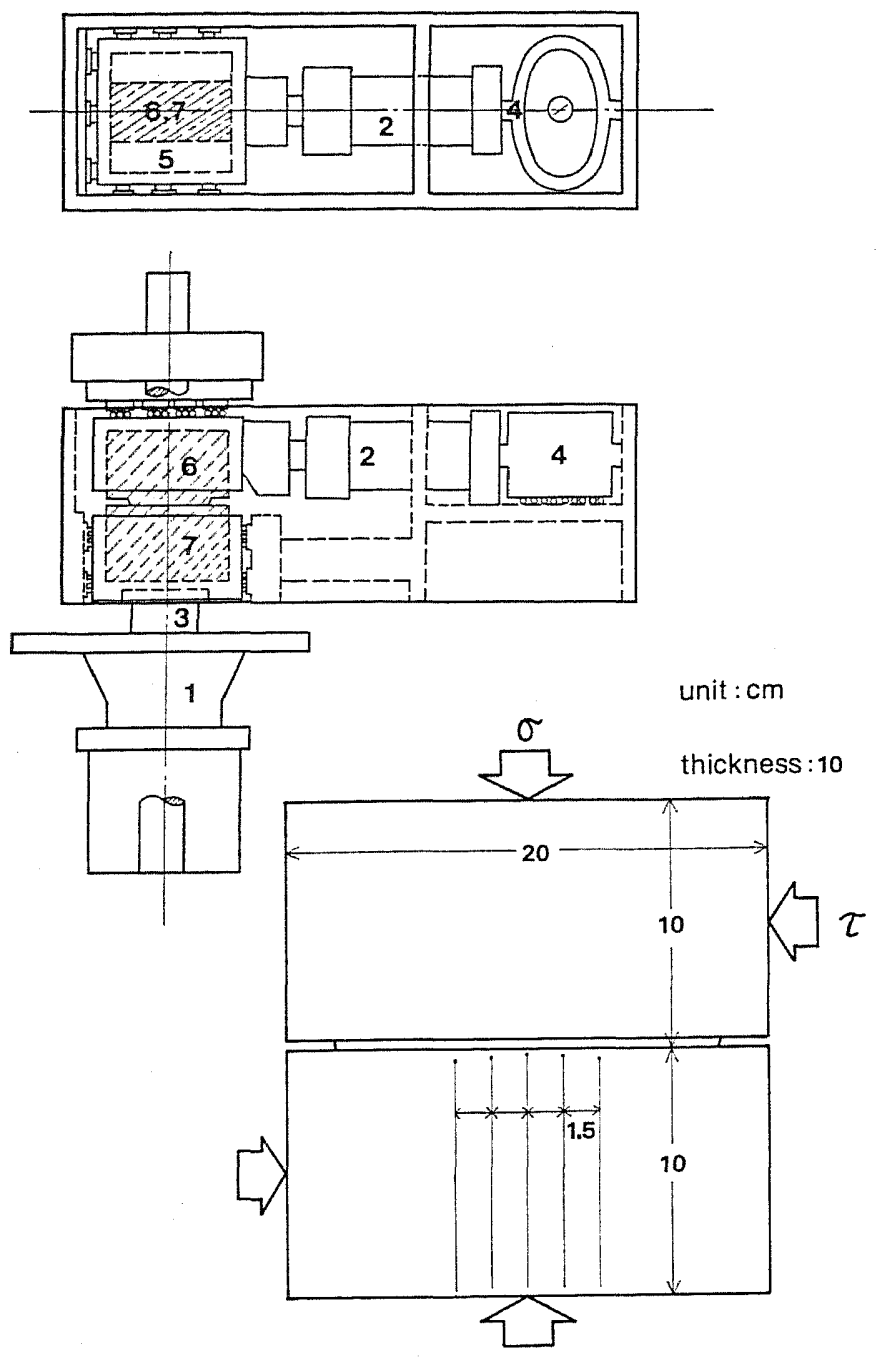

Fig. 2. The schematic figures of the testing system and the specimens used in the sliding experiments. The testing system (upper) is a direct shear apparatus which is composed of 1. a normal loading ram, 2. a shear loading ram, 3. a normal load cell, 4. a shear load cell (spring), and 5. shear boxes made of steel. 6 . and 7. in the system figure represent a pair of specimens, the details of which are illustrated in the lower figure. In orde to keep the apparent contact area constant during sliding, the circumferential corner of the upper specimen is shaped to make the bottom area of the upper block smaller than that of upper surface of the lower block. Five thermistors are buried in the lower specimen at regular intervals of $1.5 \mathrm{~cm}$ on the center line, parallel to the sliding surface. The depths of the thermistors range from 0.48 to $1.31 \mathrm{~cm}$. 
shaped to make the bottom area of the upper block smaller than that of the upper surface of the lower block (see the bottom of Fig. 2). The sliding surfaces were ground flat with 800 grit abrasives (the average grain size was about $20 \mu \mathrm{m}$ ) before the first experiment. However, the roughness of the sliding surfaces was not kept constant through all of the series of experiments, because the indentation or the ploughing due to frictional sliding occurred violently. The surface roughness was measured after one or two slidings by the tracer method (for details of the procedure, see section 2.4 ).

\subsection{Loading system}

The testing system used in our experiments was a direct shear apparatus. Figure 2 illustrates the loading system schematically. The stiffness of the shear loading system was about $4 \times 10^{4} \mathrm{kN} / \mathrm{m}$, which was measured from the differences of shear forces before and after stick-slip events. Although the stiffness of the normal loading system was not measured, it is supposed to be greater than that of

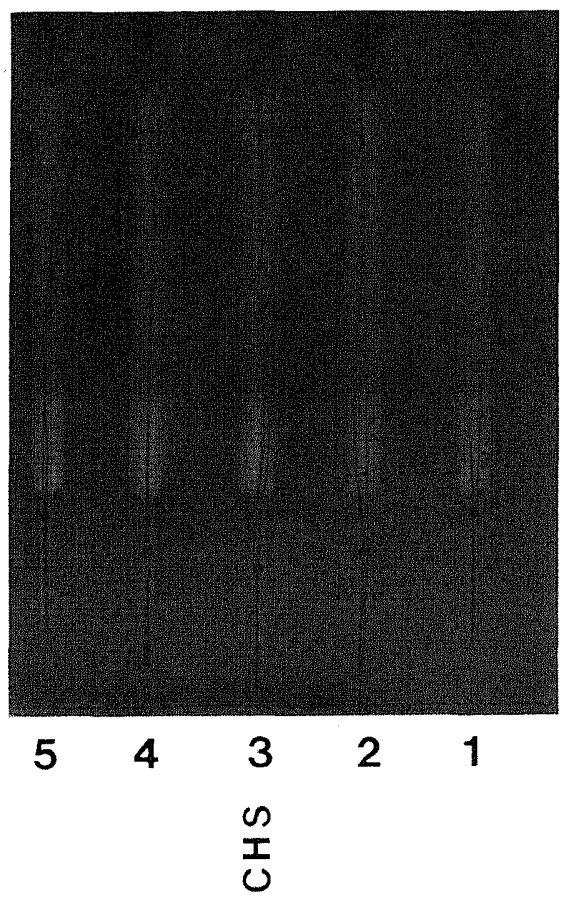

Fig. 3. A soft X-ray photograph of the specimen, which is used to measure the distance of thermistors from the sliding surface (the depth of thermistors). The accuracy of the depth of the thermistors is $0.01 \mathrm{~cm}$. Boreholes, used to hold thermistors, are drilled from the opposite side to the sliding surface by a $5 \mathrm{~mm}$-diameter drill until they reach a depth of about $7 \mathrm{~cm}$, and then they are bored by $1.5 \mathrm{~mm}$-diameter drill. The thermistors are thermally placed good contact with the rock by cementation, using a polyester resin. 
the shear loading system because of its system constitution. The upper and lower specimens were set in shear boxes made of steel. They were then piled together and put into the loading system.

\subsection{Temperature measurement}

Temperature rises after the onset of sliding were measured by thermistors buried in rocks. The thermistors are encased in $1 \mathrm{~mm}$-diameter glass beads (SSB

Table 2. Electrical properties and depth of thermistors.

\begin{tabular}{cccccc}
\hline & \multicolumn{3}{c}{ Resistance $(\mathrm{k} \Omega)$} & $\mathrm{B}^{*}$ & $\begin{array}{c}\text { Depth } \\
(\mathrm{cm})\end{array}$ \\
\cline { 2 - 5 } CHS-SS & No. & $0^{\circ} \mathrm{C}$ & $30^{\circ} \mathrm{C}$ & & \\
& 1 & 34.09 & 10.10 & 3,356 & 1.31 \\
& 2 & 34.06 & 10.63 & 3,373 & 0.77 \\
& 3 & 34.00 & 10.01 & 3,373 & 0.48 \\
& 4 & 34.13 & 10.04 & 3,376 & 0.78 \\
& 5 & 34.00 & 10.01 & 3,373 & 1.23 \\
\hline \multirow{6}{*}{ MKB-GR } & 1 & 34.00 & 9.987 & 3,380 & 0.75 \\
& 2 & 33.85 & 9.932 & 3,383 & 0.62 \\
& 3 & 34.36 & 10.08 & 3,383 & 0.53 \\
& 4 & 34.08 & 9.996 & 3,383 & 0.75 \\
& 5 & 33.87 & 9.925 & 3,386 & 1.21 \\
\hline
\end{tabular}

* Constant which determines the decreasing rate of thermistor resistance.
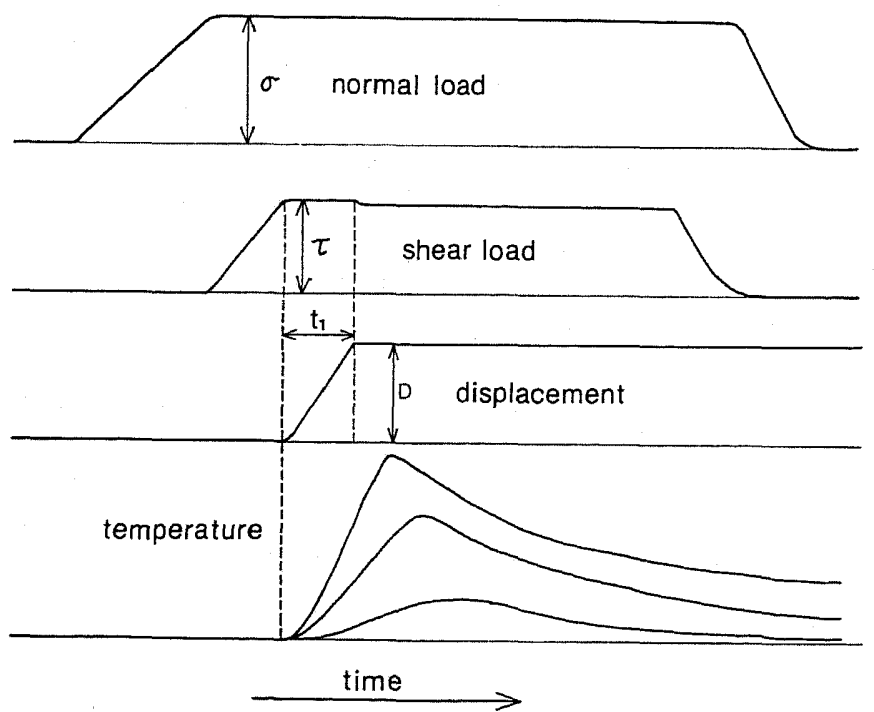

Fig. 4. The schematic illustration of the procedure in one sliding run. First, the normal load is increased and kept at a constant level. Next, the shear load is gradually applied. The magnitude of displacement is controlled at about $1 \mathrm{~cm}$ by dropping the shear force. The heat generated on the sliding surfaces is detected by the outputs from the five thermistors buried in the rock sample. 
type of Takara Thermistor Co., Ltd.). Boreholes, in which the thermistors were inserted, were drilled from the opposite side to the sliding surface of the lower specimen by a $5 \mathrm{~mm}$-diameter drill, till they reached about $7 \mathrm{~cm}$ in depth. Then small holes were drilled into it by a $1.5 \mathrm{~mm}$-diameter drill (Fig. 3). In order to fasten the thermistors with rock and to make good contact between them, they were cemented by a polyester resin. In order to estimate the heat source distribution on the sliding surface during sliding (YoshroKA, 1984), five thermistors were located on the center line parallel to the sliding direction at regular intervals of $1.5 \mathrm{~cm}$ (see the bottom of Fig. 2). The distances between the thermistors and the sliding surfaces (which will hereafter be called 'depths' of thermistors) were measured by soft X-ray photographs with an accuracy of $0.01 \mathrm{~cm}$ after all the experiments were completed (Fig. 3). Table 2 shows the electrical properties of the thermistors used, and their depths. The thermistors were calibrated at $0^{\circ} \mathrm{C}$ and $30^{\circ} \mathrm{C}$.

\subsection{Experimental procedure}

Figure 4 schematically illustrates the procedure used in an experiment, which will be called 'one sliding run'. First, the normal force was increased, and then later kept at a constant level. Next, shear force was gradually applied. When the shear force reached $50-70 \%$ of the level of normal force, sliding commenced. The magnitude of displacement was controlled at approximately $1 \mathrm{~cm}$ by dropping the shear force. The process was possible because the sliding speed of the sample was usually slow enough; the sliding duration time was about $10 \mathrm{~s}$ or longer. Even in the cases where stick-slip events occurred and the slippage of each event could not be controlled, the total magnitude of the displacement was controlled at approximately $1 \mathrm{~cm}$.

The outputs from both normal and shear load cells, and two displacement transducers (which were attached on the shear boxes) were recorded by a strip chart recorder. The temperature variations from the five thermistors were also recorded by another chart recorder. The time signals were fed to both records. The accuracy of timing was $0.1 \mathrm{~s}$. Figure 5 is an example of the records. We repeated the procedure mentioned above to normal stresses of about $100 \mathrm{MPa}$.

Two series of experiments were conducted (see Table 3); (1) sliding on a fault with no gouge (this series of experiments will be called 'Series A'), and (2) sliding on a fault with gouges ('Series B'). In series A, the surface roughness was measured and the wear particles produced during slidings were removed after one or two runs. In series $B$, the sliding runs were repeated without removal of any wear particles produced during the prior slidings. In series A, one 'cycle' consisted of three sliding runs, which were carried out under the same normal stress level. The first two runs in a cycle were repeated, so that the wear particles produced during the first sliding could be kept on the sliding surface during the second sliding. The procedure of a cycle in the series A experiment is shown in Fig. 6. 


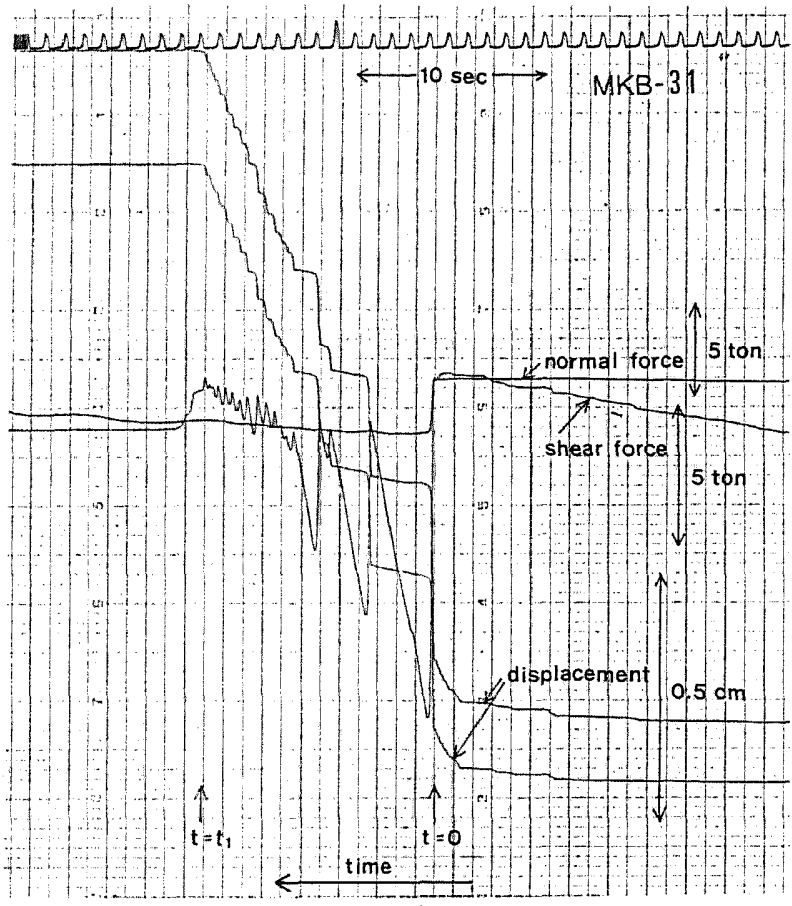

Fig. 5(a)

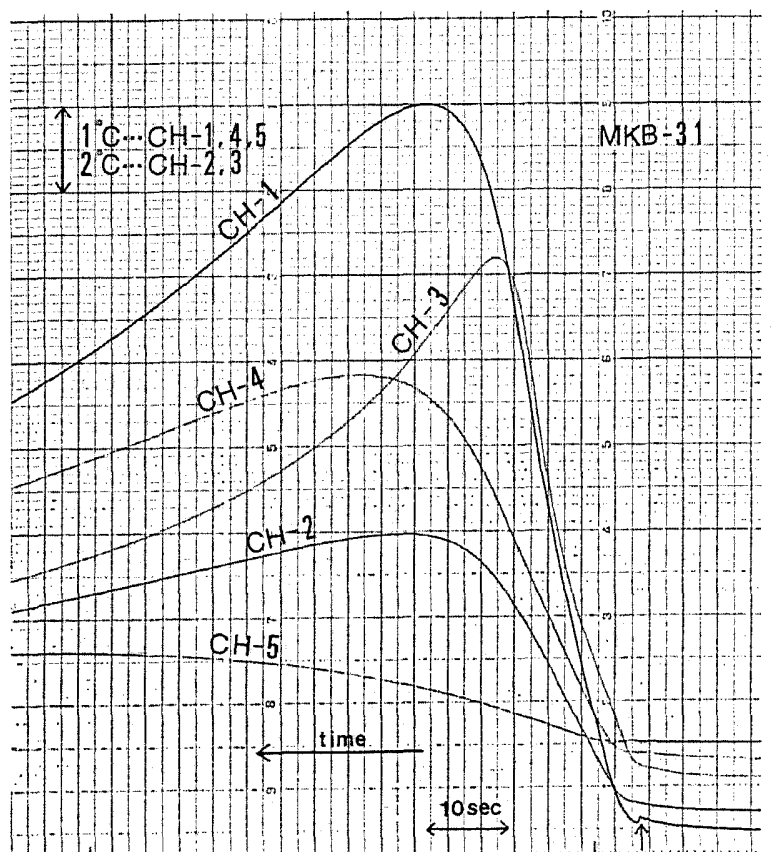

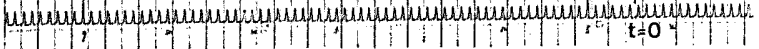

Fig. 5(b) 


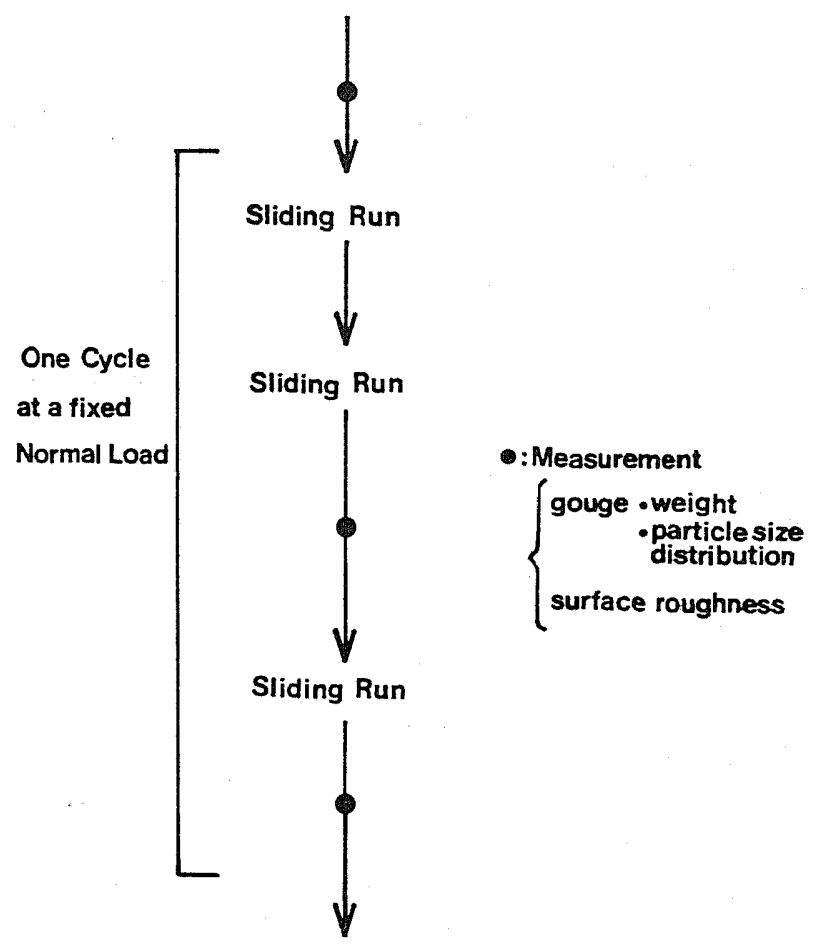

Fig. 6. Experimental procedure of series A. One cycle consists of three sliding runs under the same normal stress conditions. Measurements concerning wear particles (gouges) and the surface roughness are also carried out two times in a cycle.

\section{Results}

Table 3 shows the conditions and results of all the experiments. In Table 3, $\sigma$ and $\tau_{\mathrm{av}}$ represent the average normal and shear stresses during sliding, $D$ the total displacement, $t_{1}$ the duration time of sliding and $S$ the area of sliding surface. It should be noted that the shear stress values in Table 3 represent those of the load cell, which are different from the dynamic frictional stress on the rock surfaces during sliding. The values in the gouge column are the weights (in milligrams per unit area) of wear particles produced during the preceding run. The value $a$ represents the spatial average of the magnitude of heat sources during frictional slidings. The values of $a$ were calculated from the three-dimensional thermal conduction model (YosHIOKA, 1984).

Fig. 5. An example of strip chart records (run number MKB-31). (a) The records from the normal and shear load cells and two displacement transducers. The elevation process of the normal force is not presented in this figure, while that of the shear load is presented by a curved with a slight inclination, before the onset of sliding. (b) The temperature variations with time from the five thermistors buried in the rock sample. The base lines of the two displacement records (a) and the five temperature records (b) before the onset of sliding are offset to be distinguished. The time signals are simultaneously recorded on both charts. 


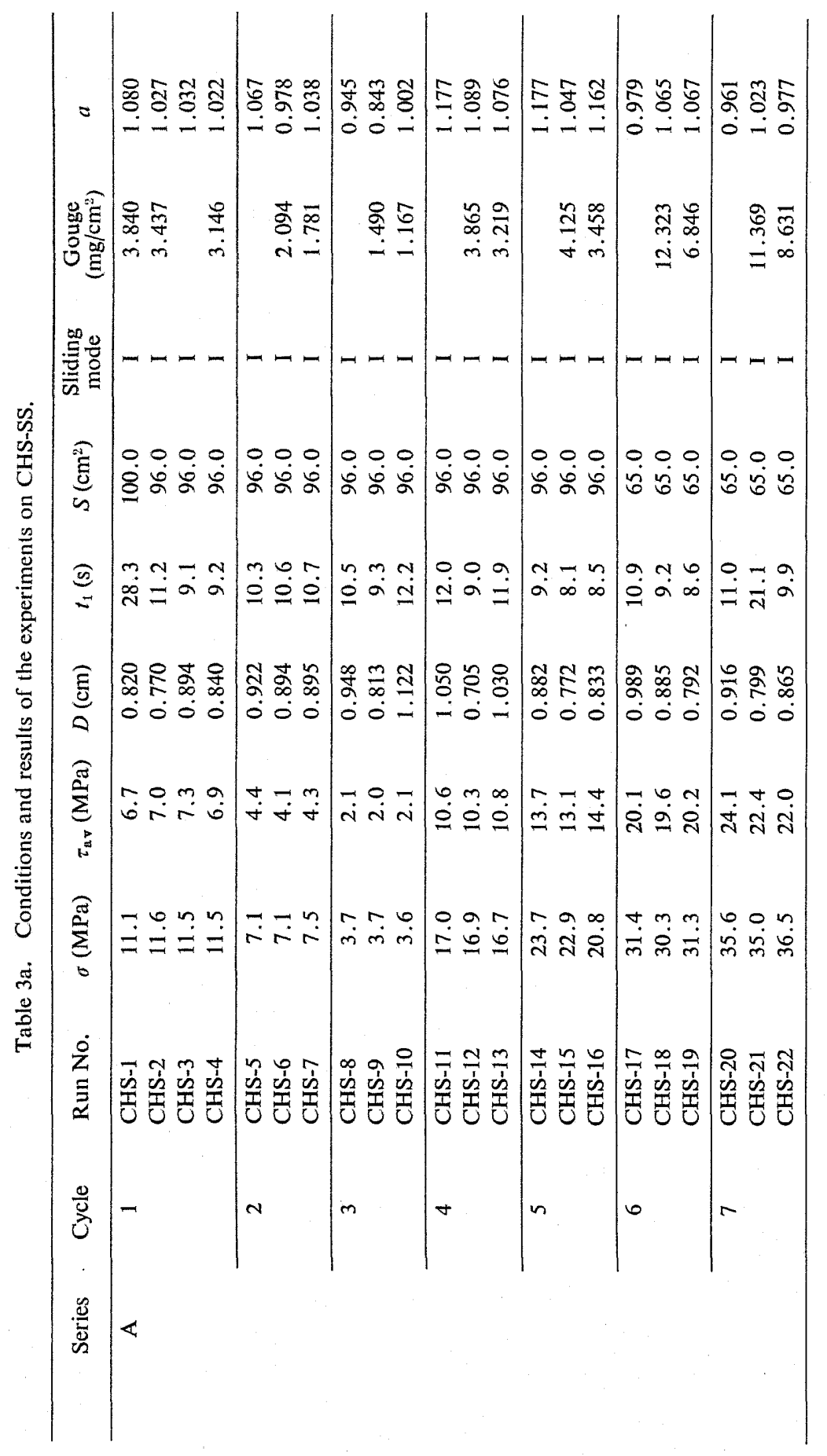




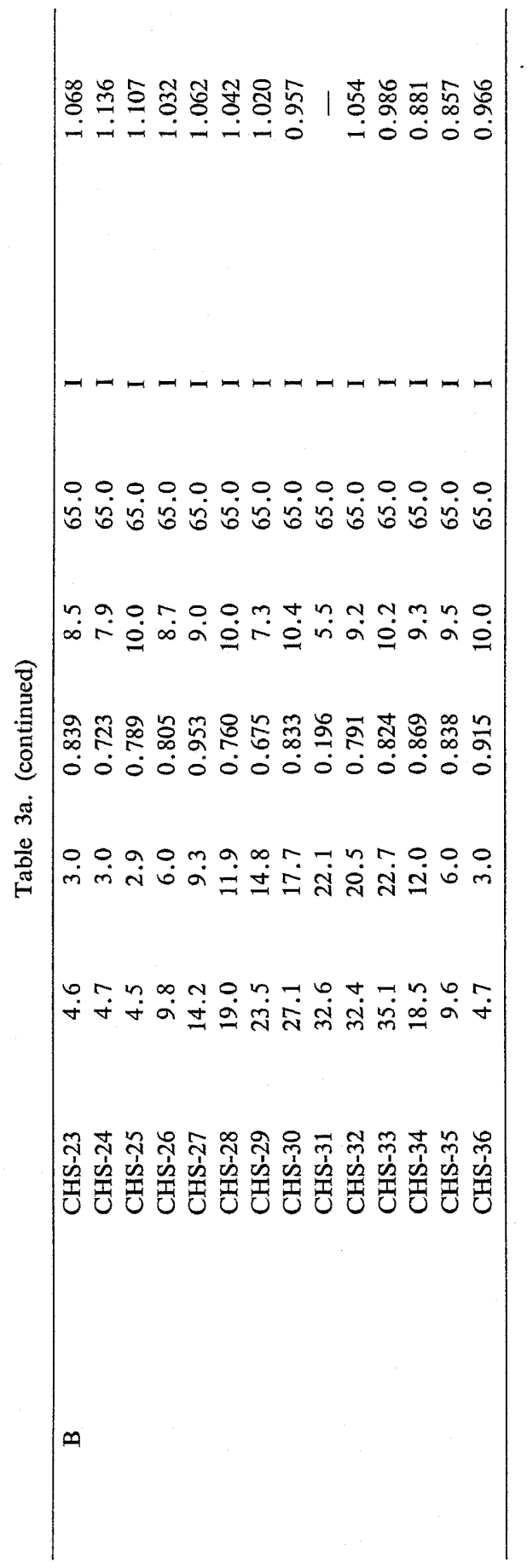




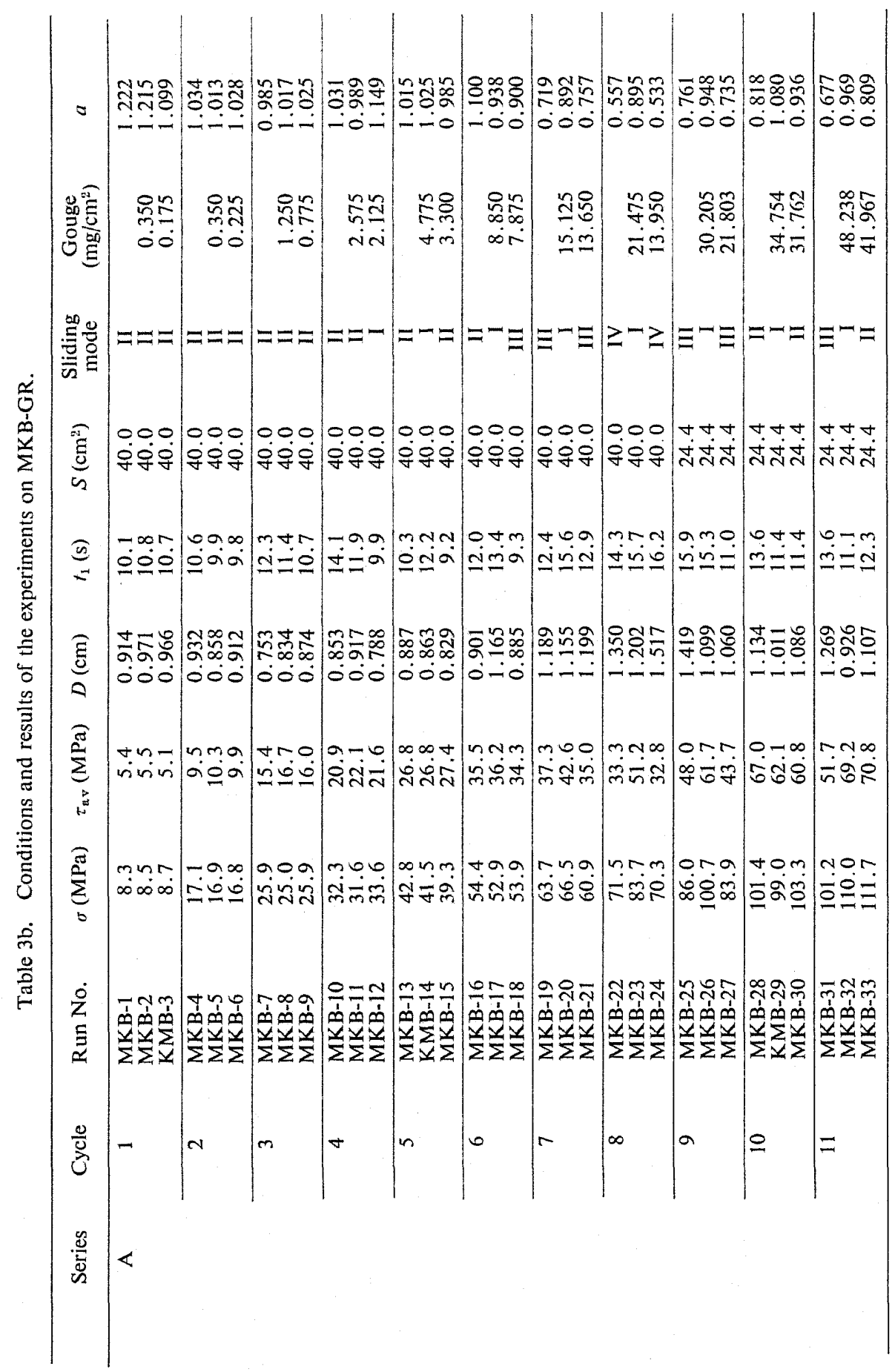




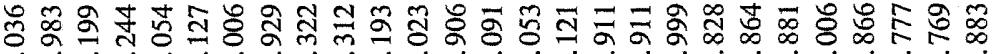

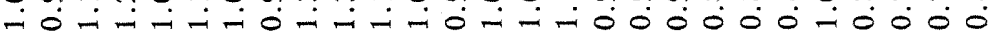

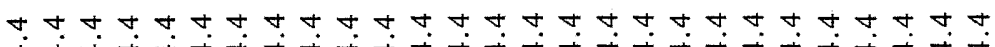

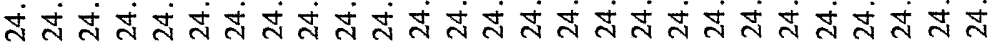

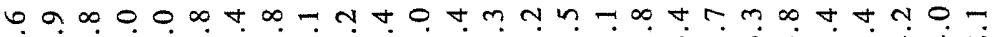

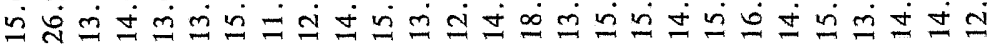

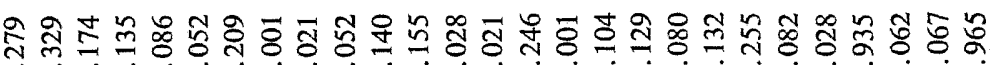

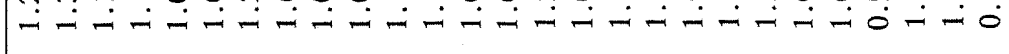
$\dot{m}$

$\infty \infty \eta \infty \forall$,

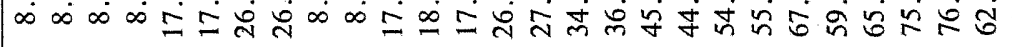

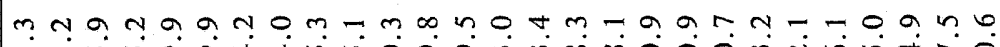

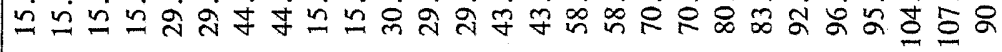

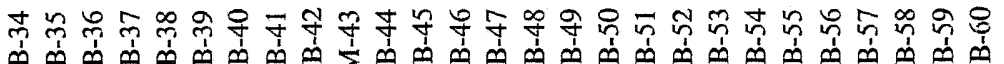
ம்

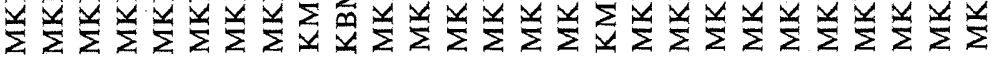


Since there seems to exist a significant relationship between the sliding mode and heat generation, we shall concentrate our discussion here on this relationship and only briefly describe other problems.
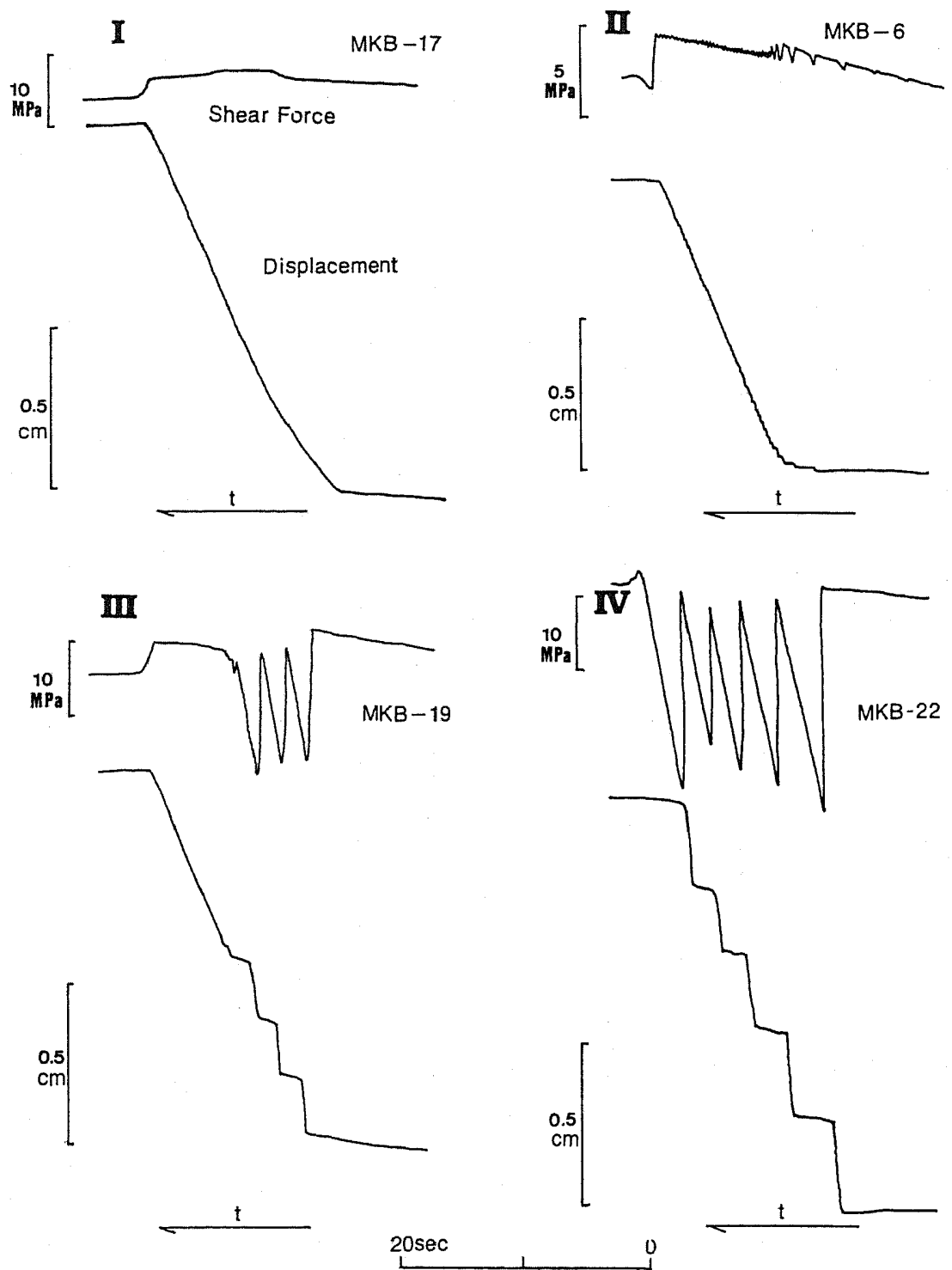

Fig. 7. Four modes of sliding, which appeared in the experiments on MKB-GR. I: Stable sliding. Shear load is kept at a nearly constant level during sliding. II: Continuous stick-slip events with small stress drop. The overall shape of displacement is similar to that of mode I. III: Episodic sliding. The sliding mode shifts from violent stick-slip to stable sliding or to a continuous stick-slip. IV: Violent stickslip events with large stress drop. 


\subsection{Sliding mode}

We classified the slidings into four modes. Mode I represents stable sliding, which begins with a very small velocity, then gradually becomes faster until it finally settles at a constant velocity, which is in the order of $0.1 \mathrm{~cm} / \mathrm{s}$. The shear load is kept at a nearly constant level during the sliding, though it slightly fluctuates in some cases. Mode II is a group of continuous stick-slip events with a small stress drop. Though the displacement in each event is small, the 'total' displacement amounts to about $1 \mathrm{~cm}$. Therefore, the overall shape of the displacement curve is similar to that of mode I. As the normal stress level becomes greater, the stress drop of each event becomes larger, and the frequency of the events lower. Mode III is called episodic sliding, because it commences as a violent stick-slip, with a cosiderable magnitude of stress drop. It rapidly shifts to a continuous stick-slip with small amplitude, or to stable sliding. Mode IV is characterized by violent stick-slip events with a large stress drop. The displacement versus time records show that a small amount of stable sliding occurred even at the time of 'stick,' in the case of modes III and IV. Typical examples of the four modes of sliding are shown in Fig. 7.

In the cases where stick-slip occurs, the displacement $D$ in Table 3 denotes the summation of small displacements accompanying each stick-slip, and the aver-

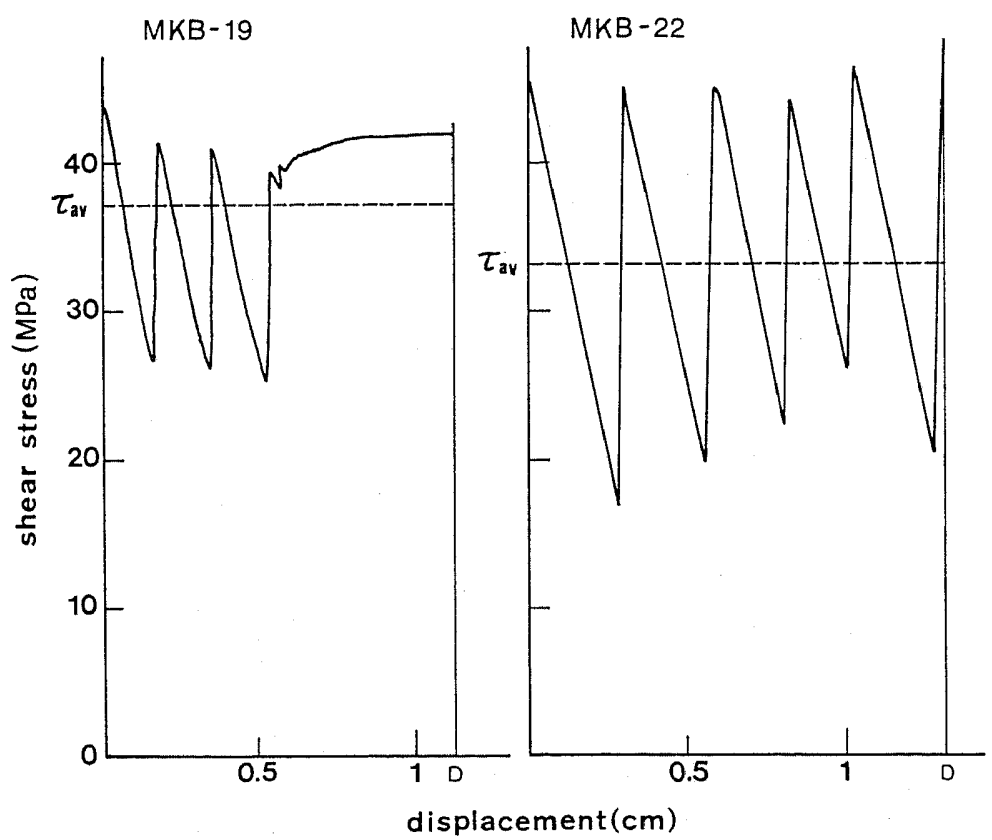

Fig. 8. Two examples of the shear force-displacement plots. MKB-19 represents the case of a sliding mode III, and MKB-22 represents mode IV. The average shear stresses $\tau_{a \text { v }}$ during sliding were obtained from these plots in the case where the violent stick-slip occurred. $D$ denotes the total displacement in a sliding run. 


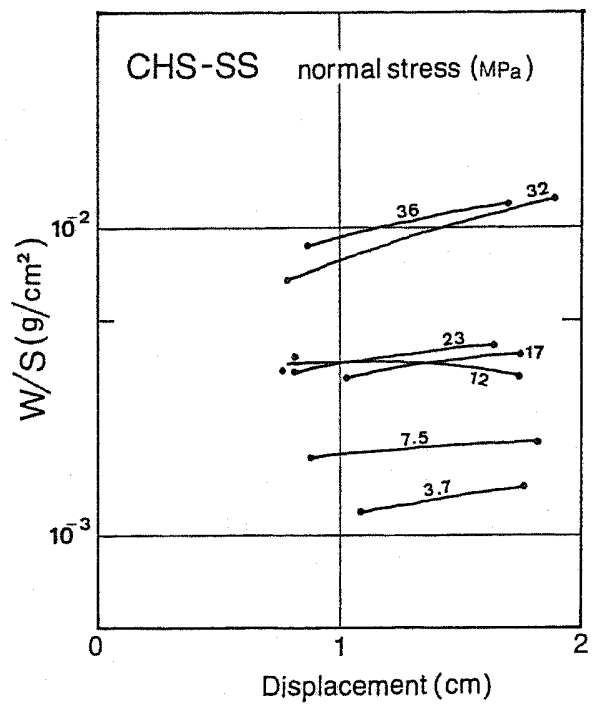

(a)

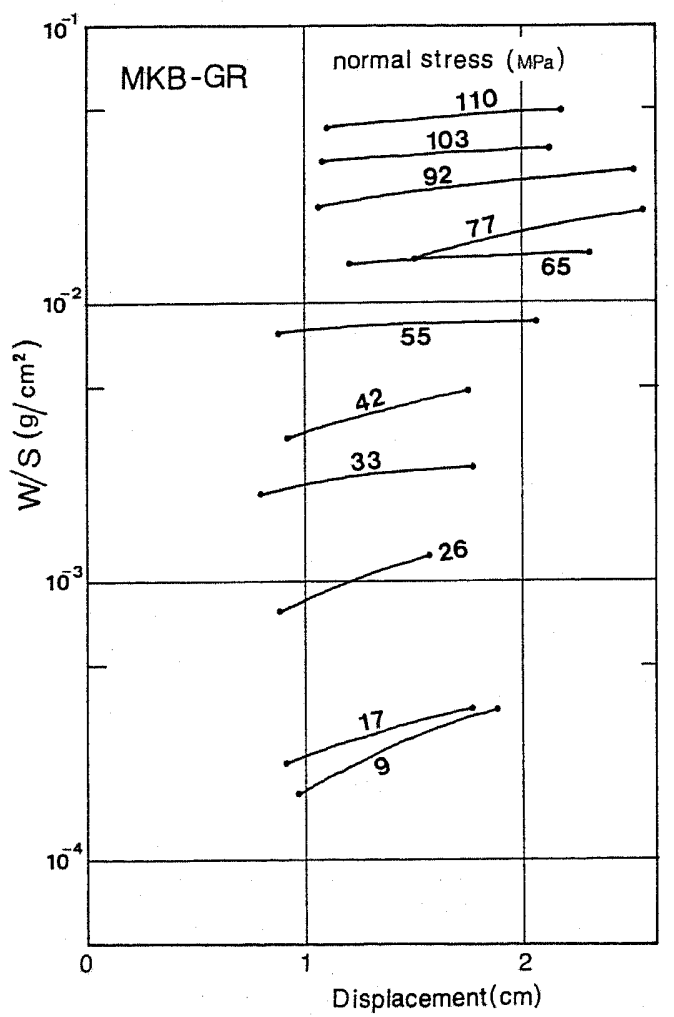

(b)

Fig. 9. Weight of gouges produced per unit area, as a function of displacement. Each curve corresponds to one cycle in the series A experiment. The numbers denote the normal stress level in MPa. 
age shear stress $\tau_{\mathrm{av}}$ is obtained from the shear force-displacement plots. Two examples of the plots are shown in Fig. 8. The area under the broken line is equal to that under the solid curves, which is the work done by the testing machine.

All the sliding modes were observed in the experiments on MKB-GR, while only mode I appeared in the experiments on CHS-SS. Mode I was seen in the following two cases on MKB-GR. The first case appeared in the second run of a 'cycle' as MKB-14, 17, 20, 23, 26, 29, and 32 in series A, which was conducted successively after the first sliding run in a cycle without the removal of gouges. The second case was observed in series B. It is notable in the series A experiments, that once gouges were removed, sliding returned to the stick-slip mode, in the cases of MKB-21, 24 and 27.

\subsection{Gouges}

Gouges were developed in all sliding modes. Figure 9 illustrates the weight of the gouges produced, per unit area, as a function of displacement. Each curve in the figure corresponds to a cycle in series A.

General observations are as follows: The amount of gouge increases with an increase in normal stress, but the rate of increase is not linear. Figure 10

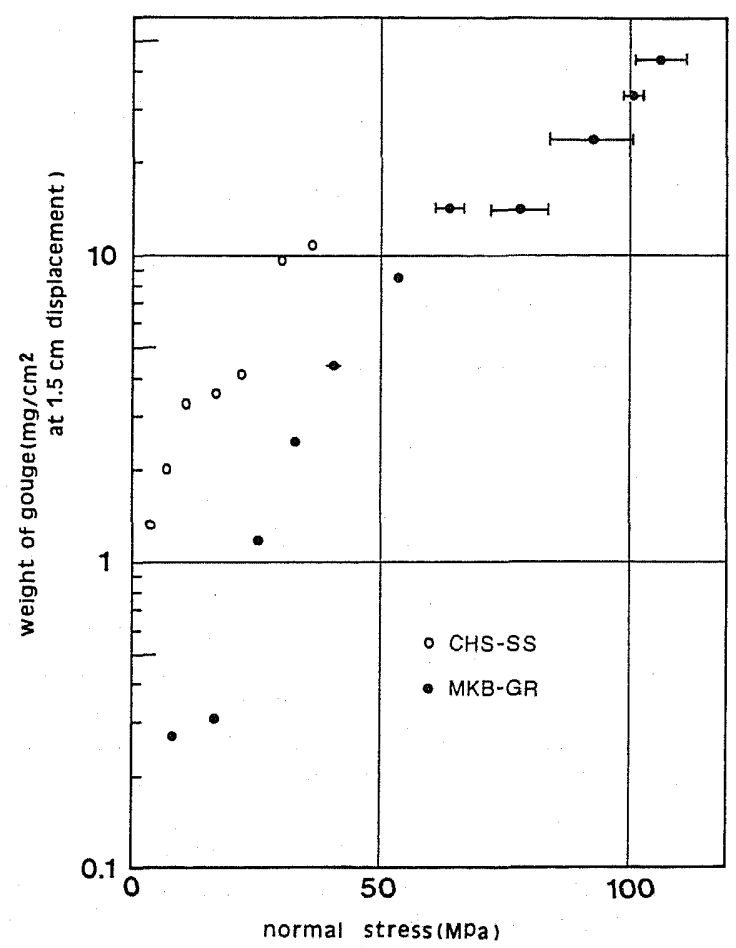

Fig. 10. The relation between the weight of gouge produced per unit area and the normal stress, at $1.5 \mathrm{~cm}$ displacement. The bars in the data of MKB-GR denote the range of normal stress. 

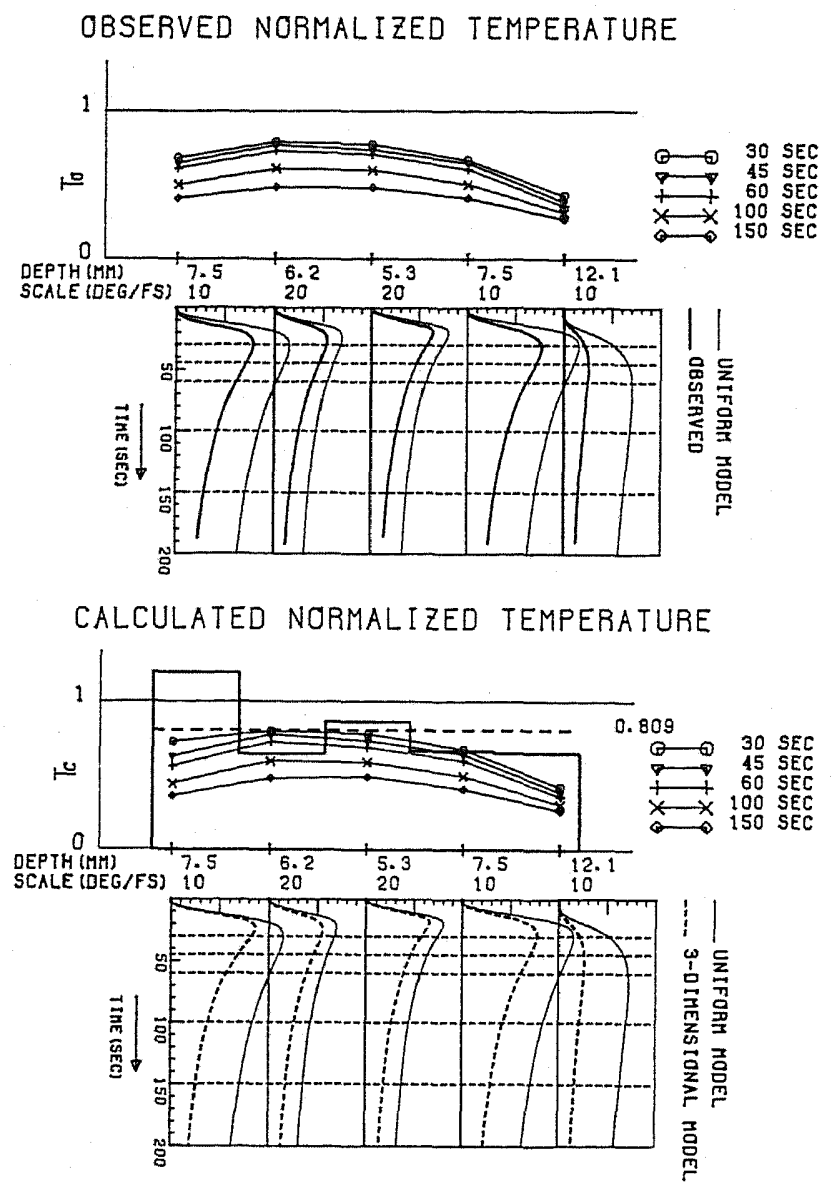

Fig. 11 (a)

Fig. 11. (a) An example of the plots of 'the observed (upper, $T_{0}(t)$ ) and calculated (lower, $\left.T_{\mathrm{c}}(t)\right)$ normalized temperatures' (see text for their definitions). The cross marks on the base line represent the positions of the five thermistors, the depths of which are shown below the marks in $\mathrm{mm}$. The temperature variations with time are also shown for each thermistor. The magnitude of degrees of temperature are given in ${ }^{\circ} \mathrm{C}$ per full scale. $T_{\mathrm{o}}(t)$ and $T_{\mathrm{c}}(t)$ for the five thermistors are calculated, using data at $30,45,60,100$, and $150 \mathrm{~s}$ after the onset of sliding. The times are shown by thin, broken lines in the figures, indicating temperature variation, according to time. The normalized temperatures at the same time are denoted by the same symbols and connected together by solid lines. The heat source distribution is shown by thick solid blocks in the lower figure. The thick broken line represents the average height of the blocks and this is the average magnitude of the heat sources, $a$. (b)-(e) Other examples of the heat source distribution. The upper and lower parts in each figure show the plots of $T_{\mathrm{o}}(t)$ and $T_{\mathrm{c}}(t)$, which are the same as (a). 
MKB-6

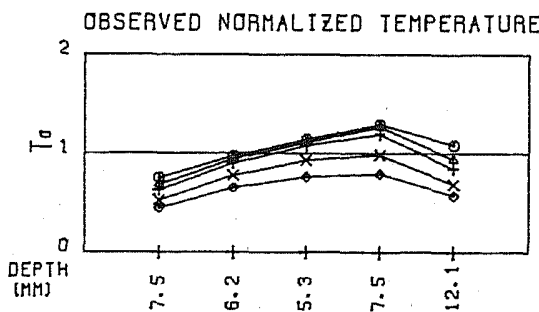

CALCULATED NORMALIZED TEMPERATURE

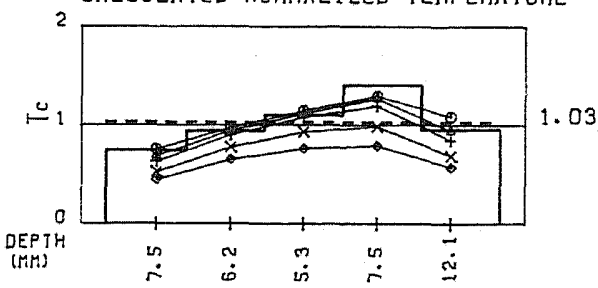

Fig. 11 (b)

$M K B-22$

OBSERVED NORMALIZED TEMPERATURE

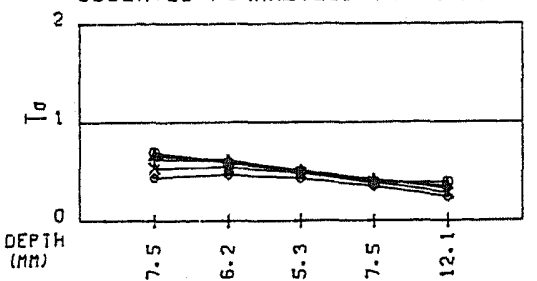

CALCULATED NORMALIZED TEMPERATURE

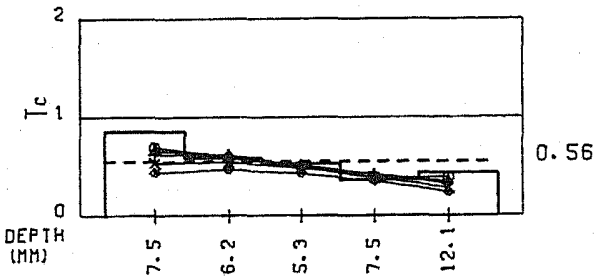

Fig. 11 (c)
$M K B-25$

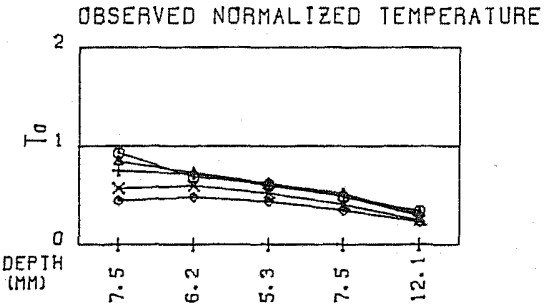

CALCULATED NORMALIZED TEMPERATURE

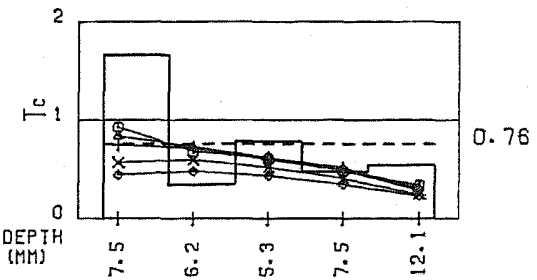

Fig. 11 (d)

$\mathrm{MKB}-32$
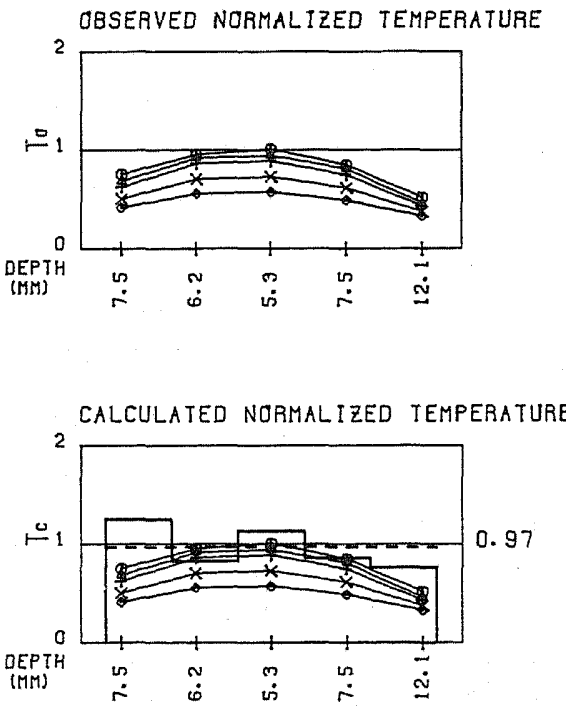

Fig. 11 (e)

denotes the relation between normal stress and the weight of the gouges at $1.5 \mathrm{~cm}$ displacement, inferred from Fig. 9. CHS sandstone produces more gouges than MKB granite under the same normal stress condition. The difference between the 
two rocks may be due to the strength of the materials. Although the amount of gouges increases with displacement, it is not proportional to the amount of displacement. The rate of increase gradually decreases with displacement.

\subsection{Heat generation}

Heat generation, due to frictional sliding, is detected as the temperature rises on the scales of the five thermistors, from which we can estimate the magnitude of the heat sources during sliding on the contact surfaces (YOSHIOKA and SHIDAHARA, 1978; LOCKNER and OKUBO, 1983). The process of estimating the magnitude of heat sources on fault surfaces was fully described in the previous paper (YosHIOKA, 1984).

According to MCKENZIE and BRUNE (1972), the one-dimensional theoretical temperature $u(x, t)$, at depth $x$ and time $t$, is expressed in the following equation.

$$
u(x, t)=\left\{\begin{aligned}
\frac{\sigma_{\mathrm{f}}}{\rho C} & \cdot \frac{D}{t_{1}}\left\{\frac{\sqrt{t}}{\sqrt{\pi k}} \exp \left(-\frac{x^{2}}{4 k t}\right)-\frac{x}{2 k} \operatorname{erfc}\left(\frac{x}{\sqrt{4 k t}}\right)\right\}, \quad 0 \leqq t<t_{1}, \\
& \cdot \frac{D}{t_{1}}\left[\left\{\frac{\sqrt{t}}{\sqrt{\pi k}} \exp \left(-\frac{x^{2}}{4 k t}\right)-\frac{x}{2 k} \operatorname{erfc}\left(\frac{x}{\sqrt{4 k t}}\right)\right\}\right. \\
& \left.-\left\{\frac{\sqrt{t-t_{1}}}{\sqrt{\pi k}} \exp \left(-\frac{x^{2}}{4 k\left(t-t_{1}\right)}\right)-\frac{x}{2 k} \operatorname{erfc}\left(\frac{x}{\sqrt{4 k\left(t-t_{1}\right)}}\right)\right\}\right], \quad t \geqq t_{1} .
\end{aligned}\right.
$$

Here $\sigma_{P}$ is the shear stress, $t_{1}$ the duration time of sliding, and $D$ the displacement. If we use the average shear stress of the testing machine, $\tau_{\mathrm{av}}$ in place of $\sigma_{f}$ in $(1)$, then $u(x, t)$ is regarded as the temperature expected, in the case where the generation of heat is uniform on the sliding surface and the entire energy supplied by the testing machine is converted to heat. Using $u(x, t)$, we define 'the observed normalized temperature' $T_{0}(t)$ as

$$
T_{\mathrm{o}}(t)=U(x, t) / u(x, t),
$$

where $U(x, t)$ is the observed temperature.

Similarly, 'the calculated normalized temperature' $T_{\mathrm{c}}(t)$ is defined as

$$
T_{\mathrm{c}}(t)=u_{3}(x, y, z, t) / u(x, t),
$$

where $u_{3}(x, y, z, t)$ is the theoretical temperature calculated from the three-dimensional thermal conduction model (YosHIOKA, 1984), in which both the finite area of sliding contact and non-nuiform distribution of heat source are taken into account. In the calculations of $u(x, t)$ and $u_{3}(x, y, z, t)$, we used the measured values shown in Table 1 for the thermal diffusivity $k$ and the density (dry) $\rho$. The specific sheat $C$, was assumed to be $0.2 \mathrm{cal} / \mathrm{gram} / \mathrm{deg}$ for both samples. Other parameters, such as $\sigma_{\mathrm{f}}\left(=\tau_{\mathrm{av}}\right), t_{1}$ and $D$ are shown in Table 3.

Figure 11(a) shows an example of the observed and calculated normalized temperatures, $T_{\mathrm{o}}(t)$ and $T_{\mathrm{c}}(t) . \quad T_{\mathrm{o}}(t)$ and $T_{\mathrm{c}}(t)$, at $t=30,45,60,100$, and $150 \mathrm{~s}$, are plotted against position. The cross marks in the figure denote the positions of the thermistors, whose depths are shown below the marks in mm. Time $t$ was 
measured from the onset of sliding. The variations in temperature with time are also shown for each thermistor. The thin solid curves represent the temperatures expected from (1), $u(x, t)$. The thick solid and broken curves are the observed temperatures, $U(x, t)$ and those derived from the three-dimensional model, $u_{3}(x$, $y, z, t)$, respectively. Distribution of heat sources during sliding was estimated and it is shown by the thick solid blocks in the lower figure. The average height of the blocks is represented by a thick broken line. This represents the average magnitude of the heat sources $a$, is given with the broken line. The value $a$ means the ratio of observed thermal energy to the total energy supplied by the testing machine.

Figures 11(b)-(e) show other examples of the estimated distribution of the heat sources. The upper and lower figures indicate the distributions of the observed and the calculated normalized temperatures, respectively. Although the pattern of heat source distribution in Fig. 11(b) is different from that shown in Fig. 11(e), $a$ is nearly equal to 1.0 in both cases. On the other hand, the values of $a$ in Figs. 11(c) and (d) are fairly less than 1.0. This indicates that the heat energy produced is significantly lower than the energy supplied by the testing machine.

As listed in Table 3, $a$ is nearly equal to 1.0 in many runs on CHS-SS. The average of $a$ is $1.038 \pm 0.076$ for series A and $1.012 \pm 0.078$ for series B of CHS-SS.

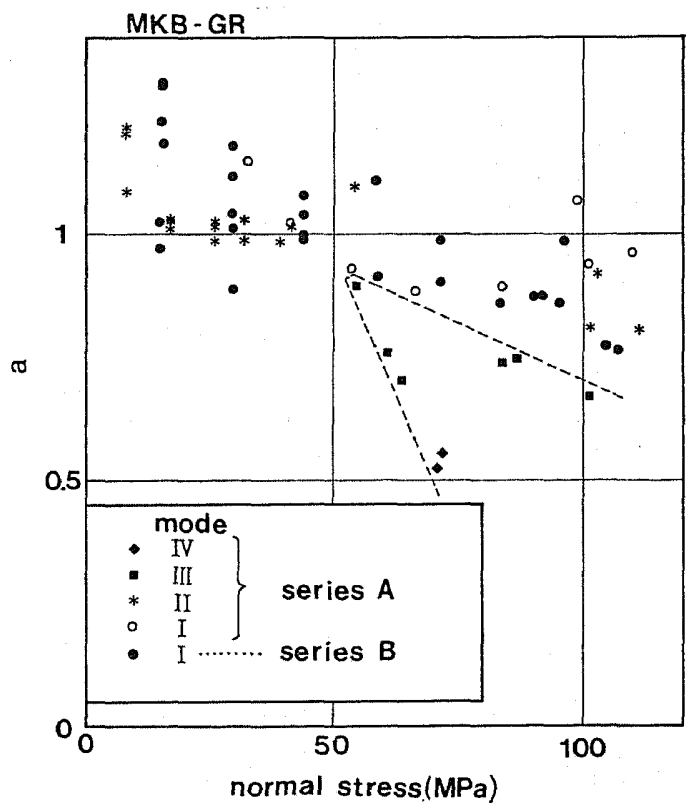

Fig. 12. The dependence of the average heat source magnitude $a$ on normal stress and on the sliding mode in MKB-GR. The effect of the sliding mode on $a$ is greater than that of normal stress. 
In the series B of MKB-GR, the average is $1.011 \pm 0.153$, although the value $a$ tends to decrease slightly as normal stress increases (Fig. 12). These facts suggest that the energy supplied by the testing machine was consumed almost entirely in the form of heat, when stable sliding occurred.

On the other hand, $a$ varies with normal stress and with the sliding mode, in series A of MKB-GR. Figure 12 illustrates the variation of $a$ with normal stress and sliding mode. The effect of the sliding mode on $a$ is likely to be greater than that of normal stress. The lowest value is about 0.5 , which is observed only in mode IV (MKB-22 and MKB-24). As mentioned in the previous subsection, the four sliding modes have been distinguished according to the magnitude of stress drop. Mode I, stable sliding, shows no stress drop during sliding, with the normal and shear stresses being kept at a constant level. Mode II, continuous stick-slip, is characterized by small stress drops when compared with the initial shear stress level. Modes III and VI include stick-slip events with a large stress drop, which reaches about half of the initial shear stress level in some cases. The generation of heat, due to frictional sliding, has a large dependence upon the magnitude of stress drop.

In Fig. 13, $a$ is plotted as a function of 'fractional stress drop,' which is defined as the ratio of stress drop to initial stress (BRUNE, 1970). $\Delta \tau$ is a representative value of the stress drop in a run, which is obtained by utilizing the formula

$$
\Delta \tau=\sum_{i} \Delta \tau_{i} \frac{d_{i}}{D}
$$

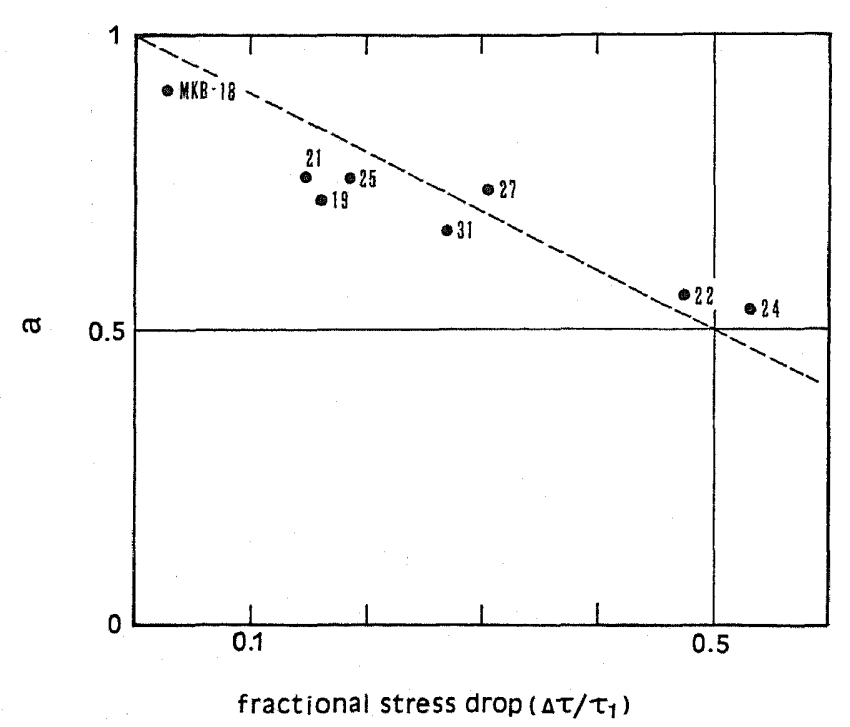

Fig. 13. Average heat source magnitude $a$ versus fractional stress drop. The numbers in the figure show the run number of the MKB-GR (Table 3). The empirical relation is given by $a=1-\Delta=/ \tau_{1}$ (shown by a broken line). 
where $d_{i}$ is the displacement and $\Delta \tau_{i}$ the stress drop, in the $i$-th stick-slip event in one run. $D$ denotes the total displacement, which is not always equal to $\sum_{i} d_{i}$ because $D$ contains displacements caused by stable sliding. $\tau_{1}$ is the initial shear stress, that is, the shear stress immediately before the onset of the first slip event. As shown in Fig. $8, \tau_{1}$ is different from the average shear stress $\tau_{a v}$ listed in Table 3.

Our experimental results (Fig. 13) show that when the stick-slip events occur with a large stress drop, energy dissipation in the form of heat is reduced. A linear relation between the average heat source magnitude $a$ and the fractional stress drop $\Delta \tau / \tau_{1}$ was found empirically from Fig. 13 and the empirical formula is given by

$$
a=1-\Delta \tau / \tau_{1}
$$

\section{Discussions}

Although the sliding mode is generally affected by normal stress (e.g., ScHOLz et al., 1972), it also depends upon machine stiffness (OHNAKA, 1973; GoodmaN and Sundaram, 1978), surface roughness (OHNAKA, 1975; BARTON, 1976) or the existence and composition of the gouges (ScHOLz et al., 1972; SUMMERS and BYERLEe, 1977; SHIMAMoto and LogAN, 1981 and many others). The results of our experiments show the strong effect of gouges on the sliding mode: the existence of gouges makes sliding stable. This fact agrees with OHNAKA's (1975) experimental results concerning soft rock (limestone).

The generation of heat, caused by the frictional sliding of rocks, is related to the sliding mode, which is characterized by the magnitude of stress drop. The conservation of energy on the sliding surface during sliding depends upon the magnitude of stress drop. ScHolz et al. (1972) also pointed out, on the basis of their experimental results, that seismic efficiency increases with the magnitude of stress drop.

The elastic energy stored in the loading frame of the testing machine is released during a slip of the stick-slip events, and this released energy is consumed in various forms: heat, elastic waves, surface energy of gouges, and so on (HussernI, 1977; SiBson, 1977b).

Let displacement and the initial and final stresses be $D, \tau_{1}$, and $\tau_{2}$, respectively, representing stick-slip on surface area $S$. The total energy released by the testing machine during slip is

$$
E=D \cdot S \cdot \frac{\tau_{1}+\tau_{2}}{2}
$$

On the other hand, the work performed by friction, which is supposed to be irreversibly converted to frictional heat (HusSEINI, 1977), is

$$
W=D \cdot S \cdot \tau_{\mathrm{f}} .
$$


ScHolz et al. (1972) called $\tau_{f}$ 'the average frictional resistive stress.' The ratio of energy dissipation, in the form of heat, to total energy used, is derived from Eqs. (6) and (7) and is written as

$$
a=\frac{W}{E}=\frac{2 \tau_{f}}{\tau_{1}+\tau_{2}} .
$$

When the frictional stress $\tau(\lambda)$ varies with the sliding displacement $\lambda$, the average frictional stress $\tau_{f}$, can be written as

$$
\tau_{\mathrm{i}}=\frac{1}{D} \int_{0}^{D} \tau(\lambda) \mathrm{d} \lambda
$$

The problem is to estimate the shape of the function $\tau(\lambda)$.

From the empirical formula (5) and the Eq. (8), $\tau_{\mathrm{f}}$ can be written as

$$
\tau_{\mathrm{f}}=\frac{\tau_{2}}{\tau_{1}} \cdot \frac{\tau_{1}+\tau_{2}}{2}=\frac{\tau_{2}}{\tau_{1}} \cdot \bar{\tau} .
$$

This relation shows that $\tau_{\mathrm{f}}$ is less than $\tau_{2}$. Therefore we can possibly estimate the shape of the function $\tau(\lambda)$ as shown in Fig. 14. In this figure, the decreasing straight line with displacement from $\tau_{1}$ to $\tau_{2}$ denotes the force (or stress) exerted by the testing machine, whose slope represents machine stiffness. The

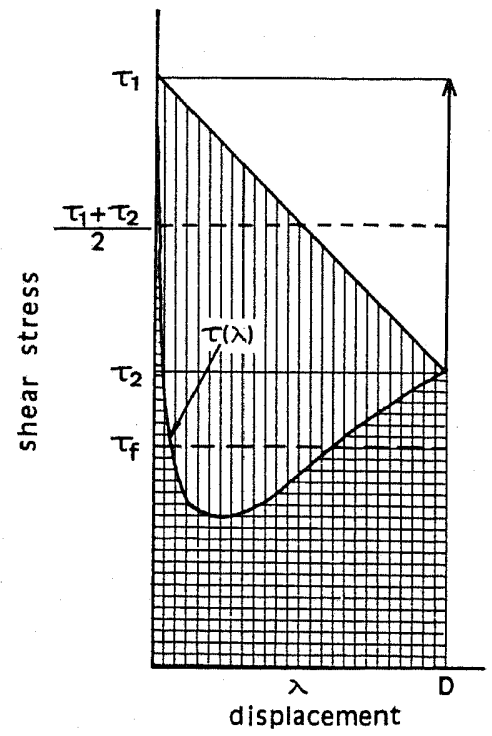

Fig. 14. The frictional resistive stress $\tau(\lambda)$ during stick-slip displacement, inferred from experimental results. The straight line represents the shear stress of the testing machine, the inclination of which represents the stiffness of the machine. The area below the straight line and that below $\tau(\lambda)$ show the total work done by the machine and the energy dissipation in the form of heat during one slip event, respectively. The average frictional resistive stress $\tau_{\mathrm{f}}$ must be less than the final stress $\tau_{2}$. 
upward curve shows the function $\tau(\lambda)$. As shown in the diagram, frictional stress rapidly goes down below the level of final stress $\tau_{2}$, and gradually recovers with displacement. Once it overcomes the force of the machine, the slip stops. At the time the motion ceases, the frictional force returns to the initial force before the slip. The reason why the mass stops at that time, in spite of the mass's inertia, is that the kinetic energy of the mass has been consumed in various energy forms (e.g., elastic wave radiation or the creating of new surfaces) during sliding. As proposed by some authors (BRUNE, 1970; YAMASHITA, 1976), the final stress is possibly greater than the frictional resistive stress during sliding. In Fig. 14, the area below the straight line (shadow area) represents the total energy supplied by the testing machine during sliding, and the area below the curve of $\tau(\lambda)$ (hatched area) represents the energy dissipation in the form of heat. The area between the two lines is called 'the available energy' (Husserni, 1977). The low value of $a$ may be explained by assuming that the shape of the function of frictional stress during sliding is given in the form of such a curve as shown in Fig. 14.

Some authors (e.g., HusseinI, 1977) have assumed that $\tau_{\mathrm{p}}$ is nearly equal to $\tau_{\mathrm{g}}$. If this is the case, the ratio of $a$ will be given from Eq. (8) as

$$
a=\frac{2 \tau_{2}}{\tau_{1}+\tau_{2}}=1-\frac{\tau_{1}-\tau_{2}}{\tau_{1}+\tau_{2}}=1-\frac{\Delta \tau}{\tau_{1}+\tau_{2}} .
$$

This relation, however, does not agree with the experimental data. Figure 15 shows the relation between $a$ and $\Delta \tau /\left(\tau_{1}+\tau_{2}\right)$. The empirical formula between both parameters is given by

$$
a=1-\nu \cdot \frac{\Delta \tau}{\tau_{1}+\tau_{2}}
$$

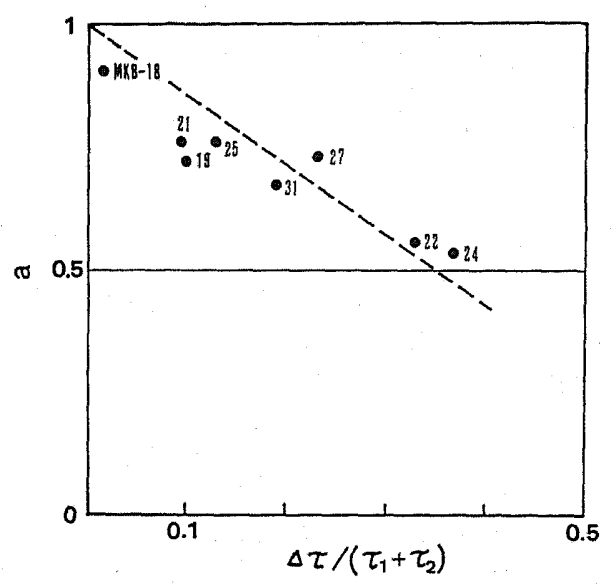

Fig. 15. The relation between $a$ and $\Delta \tau /\left(\tau_{1}+\tau_{2}\right)$. The empirical relation is $a=$ $1-1.4 \cdot \Delta \tau /\left(\tau_{1}+\tau_{2}\right)$. 
where $\nu$ is a constant larger than 1.0. Using the least square method, $\nu$ is obtained as 1.4.

At the present stage, we are unable to discuss the efficiency of seismic radiation, because fracture energy, which is necessary to create new surfaces of gouges and sliding surfaces, is quantitatively unknown, although the data concerning stable sliding qualitatively suggests that fracture energy may be rather small in comparison with the other forms of energy.

The measurement of temperature during the frictional sliding of rocks in laboratory experiments is an effective method for estimating energy conservation on the sliding surfaces and for investigating the fracturing process of earthquakes.

The author is indebted to Dr. M. Ohnaka, Dr. H. Mizutani, and Dr. M. Kikuchi for their useful discussions and for critical reading of the manuscript. He also thanks to Mr. T. Shidahara for his assistance in conducting the experiments. The experiments were done using the apparatus of Central Research Institute of Electric Power Industry, Japan.

\section{REFERENCES}

BARTON, N., The shear strength of rock and rock joints, Int. J. Rock Mech. Min. Sci., 13, 255$279,1976$.

BrACE, W. F. and J. D. ByerleE, Stick-slip as a mechanism for earthquake, Science, 153, 990992, 1966.

BRUNE, J. N., Tectonic stress and the spectra of seismic shear waves from earthquakes, J. Geophys. Res., 75, 4997-5009, 1970.

BRUNE, J. N., Earthquake modeling by stick-slip along precut surfaces in stressed foam rubber, Bull. Seismol. Soc. Am., 63, 2105-2119, 1973.

BYERLEe, J. D., The mechanics of stick-slip, Tectonophysics, 9, 475-486, 1970.

ByerLeE, J. D. and W. F. Brace, Stick-slip, stable sliding, and earthquakes, J. Geophys. Res., 73, 6031-6037, 1968.

Cardwell, R. K., D. S. Chinn, C. F. Moore, and D. L. Turcotte, Frictional heating on a fault zone with finite thickness, Geophys. J. R. Astron. Soc., 52, 525-530, 1978.

Dieterich, J. H., Time-dependent friction in rocks, J. Geophys. Res., 77, 3690-3697, 1972.

Dieterich, J. H., Earthquake mechanism and modeling, Annual Rev. Earth Planet. Sci., 2, 275$301,1974$.

DieTERICH, J. H., Modeling of rock friction, 1. Experimental results and constitutive equations, J. Geophys. Res., 84, 2161-2168, 1979a.

Dieterich, J. H., Modeling of rock friction, 2. Simulation of preseismic slip, J. Geophys. Res., 84, 2169-2175, 1979b.

ENGELDER, J. T., Microscopic wear grooves on slickensides: Indicators of paleoseismisity, $J$. Geophys. Res., 79, 4387-4392, 1974.

ENGelder, J. T. and C. H. Scholz, The role of asperity indentation and ploughing in rock friction. II. Influence of relative hardness and normal load, Int. J. Rock Mech. Min. Sci., 13, 155-163, 1976.

ENGELDER, J. T., J. M. LOGAN, and J. HANDIN, The sliding characteristics of sandstone on quartz fault-gouge, Pure Appl. Geophys., 113, 69-86, 1975.

Ermanovics, I. F., H. Helmstaedt, and A. G. Plant, An occurrence of Archean pseudotachylite from southeastern Manitoba, Can. J. Earth Sci., 9, 257-265, 1972.

FRIEDMAN, M., J. M. LOGAN, and J. A. RIGERT, Glass-indurated quartz gouge in sliding-friction 
experiments on sandstone, Geol. Soc. Am. Bull., 85, 937-942, 1974.

Goodman, R. E. and P. N. Sundaram, Fault and system stiffness and stick-slip phenomena, Pure Appl. Geophys., 116, 873-887, 1978.

HusseINI, M. I., Energy balance for motion along fault, Geophys. J. R. Astron. Soc., 49, 699-714, 1977.

IDA, Y., Analysis of stick-slip and earthquake mechanism, Phys. Earth Planet. Inter., 11, 147-156, 1975.

Johnston, D. C. and S. H. White, Shear heating associated with movement along the Alpine Fault, New Zealand, Tectonophysics, 92, 241-252, 1983.

LACHENBRUCH, A. H., Frictional heating, fluid pressure, and the resistance to fault motion, $J$. Geophys. Res., 85, 6097-6112, 1980.

LOCKNeR, D. A. and P. G. OKubo, Measurements of frictional heating in granite, J. Geophys. Res., 88, 4313-4320, 1983.

MCKenzIE, D. and J. N. BRUne, Melting on the fault planes during large earthquakes, Geophys. J. R. Astron. Soc., 29, 65-78, 1972.

OHNAKA, M., Experimental studies of stick-slip and their application to the earthquake source mechanism, J. Phys. Earth, 21, 285-303, 1973.

OHNAKA, M., Frictional characteristics of typical rocks, J. Phys. Earth, 23, 87-112, 1975.

OHNAKA, M., Application of some dynamic properties of stick-slip to earthquakes, Geophys.J.R. Astron. Soc., 53, 311-318, 1978.

Ohnaka, M., K. Yamamoto, Y. Kuwahara, and T. Hirasawa, Dynamic processes during slip of stick-slip as an earthquake fault model, Zisin II, 36, 53-62, 1983 (in Japanese with English summary).

RALEIGH, C. B., Frictional heating, dehydration and earthquake stress drops, Proceedings of Conference II, Experimental Studies of Rock Friction with Application to Earthquake Prediction, 291-304, U. S. Geol. Survey, Menlo Park, California, 1977.

Richards, P. G., Dynamic motions near an earthquake fault: A three dimensional solution, Bull. Seismol. Soc. Am., 66, 1-32, 1976.

ScHolz, C. H., Shear heating and the state of stress on faults, J. Geophys. Res., 85, 6174-6184, 1980.

SCHOLZ, C. H. and T. ENGELDER, The role of asperity indentation and ploughing in rock friction, I. asperity creep and stick-slip, Int. J. Rock Mech. Min. Sci., 13, 149-154, 1976.

Scholz, C. H., J. BeAvan, and T. C. Hanks, Frictional metamorphism, argon depletion, and tectonic stress on the Alpine Fault, New Zealand, J. Geophys. Res., 84, 6770-6782, 1979.

Scholz, C. H., P. Molnar, and T. Johnson, Detailed studies of frictional sliding of granite and implications for earthquake mechanism, J. Geophys. Res., 77, 6392-6406, 1972.

Scott, J. S. and H. I. Drever, Frictional fusion along a Himalayan thrust, Proc. R. Soc., Edinburgh, 65B, 121-142, 1954.

Shimamoto, T. and J. M. LogAN, Effects of simulated clay gouges on the sliding behavior of Tennessee sandstone, Tectonophysics, 75, 243-255, 1981.

SiBson, R. H., Generation of pseudotachylyte by ancient seismic faulting, Geophys. J. R. Astron. Soc., 43, 775-794, 1975.

Srbson, R. H., Fault rocks and fault mechanisms, J. Geol. Soc. London, 133, 191-214, 1977a.

SiBson, R. H., Kinetic shear resistance, fluid pressures and radiation efficiency during seismic faulting, Pure Appl. Geophys., 115, 387-410, 1977b.

Sibson, R. H., Power dissipation and stress levels on faults in the upper crust, J. Geophys. Res., 85, 6239-6247, 1980.

SUMmERs, R. and J. BYERLEE, A note on the effect of fault gouge composition and the stability of frictional sliding, Int. J. Rock Mech. Min. Sci., 14, 155-160, 1977.

TeufeL, L. W. and J. M. LoGAN, Effect of displacement rate on the real area of contact and temperatures generated during frictional sliding of Tennessee sandstone, Pure Appl. Geophys., 116, $840-865,1978$. 
WALSH, J. B., Stiffness in faulting and in friction experiments, J. Geophys. Res., 76, 8597-8598, 1971.

Wu, F. T., L. Blatter, and H. Roberson, Clay gouges in San Andreas Fault system and their possible implications, Pure Appl. Geophys., 113, 87-95, 1975.

YAMASHITA, $T$., On the dynamic process of fault motion in the presence of friction and inhomogeneous initial stress. Part 1. Rupture propagation, J. Phys, Earth, 24, 417-444, 1976.

YoshrokA, N., A method for estimating the shear stress distribution from temperature measurements during sliding of rocks, J. Phys. Earth, 32, 1-12, 1984.

Yoshioka, N. and T. Shidahara, Measurement of frictional heating generated during stable sliding, Prog. Abstr., Seismol. Soc. Jpn., No. 2, p. 104, 1978 (in Japanese). 